\title{
Development of the damaged glycocalyx hypothesis - A review
}

\author{
AJ Drake-Holland ${ }^{1}$ and MIM Noble ${ }^{2 *}$ \\ ${ }^{1}$ Robert Gordon University, Aberdeen, UK \\ ${ }^{2}$ University of Aberdeen, UK
}

\begin{abstract}
We have reviewed the literature from 2008 up to 2018 that is relevant to our 2008 postulate that arterial glycocalyx dysfunction is the first step in the atherothombotic process. It would appear from this survey that the hypothesis is still a reasonable one. Vascular glycocalyx dysfunction has been shown to alter fluid exchange with tissue and is involved in oedema and iflammation formation, leading to revised equations for the Starling principle. Interactions between anticoagulant factors bound to the vascular glycocalyx have been postulated to protect vessels from intravascular thombosis. The glycocalyx, according to all authors that we have reviewd, is negatively charged, but we found no measurement of glycocalyx electrical potential. This negativity is suggested as a mechanism for repulsion of adhesion molecules. We suggest that future work should focus on the electrophysiology, e.g., endothelial cells are highly negatively charged, as are leukocytes and platelets. We postulate that electrostatic repulsion of like charges may play an important role in the protective function of the vascular glycocalyx, and its failure during dysfunction may contribute to the initiation of arterial disease.
\end{abstract}

\section{Introduction}

In 2008, inspired by the work on vascular glycocalyx by Vink, we collaborated with him to postulate that arterial glycocalyx dysfunction is the first step in the atherothombotic process [1]. Our previous experience of the glycocalyx had been the finding that high luminal blood glucose concentration in an artery inhibited shear stress induced arterial dilatation for which the endothelial glycocalyx acts as mechanotransducer [2]. As this function is mediated by nitric oxide (NO) release, we reasoned that its inhibition by hyperglycemia might lead to the reduced protection of arteries by the NO and contribute to the predilection to arterial disease in diabetes mellitus. The result [2] also provided an explanation for the predilection for the disease to be sited in those parts of the arterial tree with low shear stress [3]. That the vascular glycocalyx (delineated by Vink \& Duling [4]) was necessary for shear stress induced arterial dilatation had been established by the fact of its abolition by hyaluronidase, hyaluron being a vital component of the gel [5]. The endothelial glycocalyx is a gel including a network of membrane-bound proteoglycans and glycoproteins, covering the endothelium luminally. Both endothelium- and plasmaderived soluble molecules integrate into this gel mesh. Insight has been gained into the role of the glycocalyx in vascular physiology and pathology, including mechanotransduction, hemostasis, signaling, and interactions between blood cells and the vessel wall. There had also been hints of a possible role of degradation of the glycocalyx by oxidized low density lipoprotein [6,7], and hyperglycemia [8]. There have also been postulates that endothelial cell glycocalyx modulates immobilization of leukocytes at the endothelial surface [9] and that the glycocalyx had vasculoprotective properties [10]. The purpose of the present review is to indicate evidence since 2008 that is relevant to the hypothesis that arterial glycocalyx dysfunction is the first step in the atherothombotic process [1].

\section{Vascular permeability aspects}

The discovery of the vascular glycocalyx has led to a modification of the Starling principle [11] governing the balance between opposing oncotic and hydrostatic pressures. This is determined particularly by the properties of the vascular barrier. Endothelial glycocalyx, located with a thickness of at least $200 \mathrm{~nm}$ on the luminal side of healthy vasculature, plays a vital role in vascular permeability by constituting the vascular barrier together with the endothelial cells themselves [12]. Experiments confirm that the effect of plasma and interstitial fluid colloid osmotic pressure on micro vascular fluid exchange is much less than predicted by the conventional Starling principle, and is in agreement with modern models [13]. A more recent proposal is that in arterioles and capillaries, there is very little fluid and colloid extravasation due to the endothelial surface layer formed by the glycocalyx and albumin [14]. Woodcock \& Woodcock [15] found that a revised equation for the Starling principle led to improved composition of resucitation fluid, of which the main feature was the inclusion of albumen.

\section{Biochemical and molecular aspects}

Albumen and heperan sulphate in the glycocalyx are negatively charged and repel adhesion molecules such as th platelet-endothelialcell-adhesion molecule (PECAM), the vascular cell adhesion molecule (VCAM) and the intercellular adhesion molecule (ICAM). Thrombosis within vessels can be a side effect of the mechanisms to inhibit bleeding from wounds by the classic coagulation cascade and through platelet action. The glycocalyx has an important function in that it protects

Correspondence to: MIM Noble, Department of Medicine and Therapeutics, Polwarth Building, Foresterhill, Aberdeen AB25 2ZH, UK. E-mail: mimnoble@ mac.com

Received: February 08, 2018; Accepted: February 27, 2018; Published: March 15, 2018 
vessels from intravascular thrombosis. Antithrombin III, an inhibitor of thrombin and activated factors IX and X, bind to the glycocalyx. Heparan sulphate and heparin cofactor II are present in the glycocalyx. This anticoagulant action is reinforced by the endothelial cells which produce thrombomodulin and chondroitin sulphate, which interacts with thrombin to activate the protein $\mathrm{C}$. The tissue factor pathway inhibitor binds via heparin sulphates to inhibit factors VIIa and Xa [16].

\section{Electrophysiological aspects}

The Bio-electric Law [17] has highlighted the hitherto neglected role of electrons in physiology. All living cells have a negative transmembrane potential due to an excess of negative charge carried by electrons generated by mitochondria during oxidative phosphorylation. In the polarised endothelial cell, the trans membrane potential is approximately $-80 \mathrm{mV}$ [18], and although depolarisation has been studied using high extracellular potassium ion concentrations, there do not seem to be any measurements of depolarisation during more physiological stimuli such as increased shear stress. This would appear to be an area requiring research focusing. Also, although all authors agree that the glycocalyx is negatively charged, there appear to be no measurements of its electrical potential.

The importance of this negative charge follows from the fact that the blood cells that are potentially damaging to the endothelium and the platelets and leukocytes. The membrane potential of platelets in physiological buffer was estimated to be -52 to $-60 \mathrm{mV}$ [18]. Estimates of membrane potential in white blood cells vary from -45 to $-86 \mathrm{mV}$ [19]. These negatively charged cells are presumably subject to electrostatic repulsion with respect to the negatively charged glycocalyx (electrical potential unknown) and the endothelial cell with trans membrane potential of $-80 \mathrm{mV}$, when polarized at extracellular potassium ion $\left(\mathrm{K}^{+}\right)$ concentration of $4 \mathrm{mM}$ [20]. This could explain, at least in part, the modulation of immobilization of leukocytes at the endothelial surface [21]. Another apparently neglected area of research is related to the lack of measurements of possible depolarisation of endothelial cells during physiological events such as shear stress induced vasodilatation. Depolarisation, according to the Bio-electric theory is due to electron outflow from the cell. If so, it would be likely that electron gain by the glycocalyx would result, contributing to glycocalyx electrical negative charge.

\section{Degradation of the glycocalyx}

Some pathological conditions have been associated with glycocalyx degradation. The effect of diabetes mellitus has been the most explored of these conditions, in which endothelial glycocalyx damage coincides with microalbinuria in type 1 diabetes [22-24]. The loss of glycocalyx during hyperglycaemia can cause intravascular coagulation [25]. Microalbinuria may be a sign of general loss of control of permeability [26]; endothelial damage occurs in diabetic kidney disease [27]. This is consistent with the claim that endothelial glycocalyx protects against myocardial edema [28]. The possibility of glycocalyx degradation in other pathological in vitro and in vivo models and patients are underging or require exploration.

In of hepatic ischaemia and reperfusion injury, glycocalyx degradation has been postulated to follow from the effect of endothelial glycocalyx degredation by reactive species [29]. In the case of the inflammation, protein $\mathrm{C}$ depletion and fibrinolysis in trauma patients, high levels of syndican-1 are found, which is marker endothelial glycocalyx degradation [30]. Patients with severe injury and early traumatic coagulopathy display endothelial glycocalyx degradation, which induces endogenous heparinisation [31]. Even erythrocytes with a transmural potential of about $-10 \mathrm{mV}$ [32], which normally stream clear of the glycocalyx can penetrate into the glycocalyx during impaired microvascular perfusion [33]

\section{Evidence compatible with glycocalyx dysfuncion as the first step in the initiation of vascular disease.}

Shredding of the glycocalyx appears as an essential initial step in the pathophysiology of atherosclerosis and microangiopathic complications of diabetes mellitus, as well as in chronic venous disease $[34,35]$. Atherosclerosis risk factors are hypercholesterolemia low density lipoprotein (LDL), hyperglycemia, inflammation, and altered low shear stress, all of which can damage glycocalyx [36]. This may allow LDL and leukocytes to penetrate to the subendothelial space initiating inflammation [37] and atheroma plaque formation [34]. Leukocytes may also migrate into the venous wall and initiate inflammation leading to morphologic and functional venous changes of the chronic venous disease. It has been claimed that treatment with sulodexide (a glycosaminoglycan) improves peripheral arterial obstructive disease and diabetic nephropathy with albuminuria [34]. Physicians are now considering early treatment of vascular diseaase by targeting treatment to the glycocalyx [38], e.g., sulodexide[34]. Not only drugs but normalisation of high shear stress is being considered as therapy [36].

\section{Conclusion}

It appears that the original hypothesis that arterial glycocalyx dysfunction is the first step in the atherothrombotic process is still to be considered as reasonable. The latest expression of this appears from Zhanga et al [39]. As far as fundamental understanding of the underlying mechanisms of vascular endothelial glycocalyx physiology and pathophysiology are concerned, the main recommendations for future research ought to be the answering of the many unanswered questions on the electrostatic and electrophysiological aspects.

\section{References}

1. Noble MI, Drake-Holland AJ, Vink H (2008) Hypothesis: arterial glycocalyx dysfunction is the first step in the atherothrombotic process. QJM 101: 513-518. [Crossref]

2. Kelly R, Ruane-O’Hora T, Noble MIM, Drake- Holland AJ, Snow HM (2006) Differential inhibition by hyperglycaemia of shear stress- but not acetylchominemediated dilatation in the iliac artery of the anaesthetized pig. $J$ Physiol 573:133-145. [Crossref]

3. Caro CG, Fitz-Gerald JM, Schroter RC (1969) Arterial wall shear and distribution of early atheroma in man. Nature 223: 1159-1160. [Crossref]

4. Vink H, Constantinescu AA, Spaan JA (2000) Oxidized lipoproteins degrade the endothelial surface layer : implications for platelet-endothelial cell adhesion. Circulation 101: 1500-1502. [Crossref]

5. Mochizuko S. Vink H. Hiramatsu O. Kajita T. Shigeto F, et al. (2003) Role of hyaluronic acid glycosaminoglycans in shear-induced endothelium-derived nitric oxide release. Am J Physiol Heart Circ Physiol 285: H722-H726. [Crossref]

6. Vink H, Constantinescu AA, Spaan JA (2000) Oxidized lipoproteins degrade the endothelial surface layer. Circulation 101:1500-1505. [Crossref]

7. Constantinescu AA, Vink H, Spaan JA (2001) Elevated capillary tube hematocrit reflects degradation of endothelial cell glycocalyx by oxidized LDL. Am J Physiol Heart Circ Physiol 280: H1051-1057. [Crossref]

8. Nieuwdorp M, van Haeffen WE, Gouverneur F, Mooij HL, van Lieshout MH, et al. (2006) Loss of endothelial glycocalyx during acute hyperglycaemia coincides with endothelial dysfunction and coagulation activation in vivo. Diabetes 55: 480-486. [Crossref]

9. Constantinescu AA, Vink H, Spaan JA (2003) Endothelial cell glycocalyx modulates immobilization of leukocytes at the endothelial surface. Arterioscler Thromb Vasc Biol 23: 1541-1547. [Crossref] 
10. Gouverneur M, Berg B, Nieuwdorp M, Stroes E, Vink H (2006) Vasculoprotective properties of the endothelial glycocalyx: effects of fluid shear stress. J Intern Med 259: 393-400. [Crossref]

11. Becker BF, Chappell D, Jacob M (2010) Endothelial glycocalyx and coronary vascular permeability: the fringe benefit. Basic Res Cardiol105: 687-701. [Crossref]

12. Starling EH (1896) On the Absorption of Fluids from the Connective Tissue Spaces. $J$ Physiol 19: 312-326. [Crossref]

13. Levick JR, Michel CC (2010) Microvascular fluid exchange and the revised Starling principle. Cardiovasc Res 87: 198-210. [Crossref]

14. Jacob M, Bruegger D, Rehm M, Stoeckelhuber M, Welsch U, et al. (2007) The endothelial glycocalyx affords compatibility of Starling's principle and high cardiac interstitial albumin levels. Cardiovasc Res 73: 575-586. [Crossref]

15. Woodcock TE, Woodcock TM (2012) Revised Starling equation and the glycocalyx model of transvascular fluid exchange: an improved paradigm for prescribing intravenous fluid therapy. Brit J Anaesth 108: 384-394. [Crossref]

16. Alphonsus CS, Rodseth RN (2014) The endothelial glycocalyx: a review of the vascular barrier. Anaesthesia 69: 777-784. [Crossref]

17. Noble MIM. The Bioelectric Law. Conference Paper.

18. Friedhoff LT, Sonenberg M (1983) The membrane potential of human platelets. Blood 61: 180-185. [Crossref]

19. Ehrenberg B, Montana V, Wei MD, Wuskell JP, Loew LM (1988) Membrane potentia can be determined in individual cells from the nernstian distribution of cationic dyes. Biophys J 53: 785-794. [Crossref]

20. Callies C, Fels J, Liashkovich I, Kliche K, Jeggle P, et al. (2011) Membrane potential depolarization decreases the stiffness of vascular endothelial cells. J Cell Sci 124: 19361942 [Crossref]

21. Constantinescu AA, Vink H, Spaan JA (2003) Endothelial cell glycocalyx modulates immobilization of leukocytes at the endothelial surface. Arterioscler Thromb Vasc Biol 23: 1541-1547. [Crossref]

22. Nieuwdorp M, Mooij HL, Kroon J, Atasever B, Spaan JA, et al. (2006) Endothelial glycocalyx damage coincides with microalbuminuria in type 1 diabetes. Diabetes 55: 1127-1132. [Crossref]

23. Noble MIM, Drake-Holland AJ (2010) Hyperglycaemia and the vascular glycocalyx: the key to microalbuminuria and cardiovascular disease in diabetes mellitus? $\mathrm{Br}$ Diabetes Vasc Dis 10: 66-70.

24. Satchell SC, Tooke JE (2008) What is the mechanism of microalbuminuria in diabetes: a role for the glomerular endothelium? Diabetologia 51: 714-725. [Crossref]

25. Nieuwdorp M, van Haeften TW, Gouverneur MC, Mooij HL, van Lieshout MH, et al. (2006) Loss of endothelial glycocalyx during acute hyperglycemia coincides with endothelial dysfunction and coagulation activation in vivo. Diabetes 55: 480-486. [Crossref]
26. Perrin R, Harper S, Bates D (2007) A role for the endothelial glycocalyx in regulating microvascular permeability in diabetes mellitus. Cell Biochem Biophys 49: 65-72. [Crossref]

27. Fu J, Lee K, Chuang PY, Liu Z, He JC (2015) Glomerular endothelial cell injury and cross talk in diabetic kidney disease. Am J Physiol Renal Physiol 308: F287-297. [Crossref]

28. van den Berg BM, Vink H, Spaan JA (2003) The endothelial glycocalyx protects against myocardial edema. Circ Res 92: 592-594. [Crossref]

29. van Golena RF, van Gulika TM, Hegerab M (2012) Mechanistic overview of reactive species-induced degradation of the endothelial glycocalyx during hepatic ischemia/ reperfusion injury. F Raf Biol 52:1382-1402. [Crossref]

30. Johansson P, Stensballe J, Rasmussen L, Ostrowski S (2011) A High admission syndecan-1 level, a marker of endothelial glycocalyx degradation, is associated with inflammation, protein $\mathrm{C}$ depletion, fibrinolysis, and increased mortality in trauma patients. Annals Surg 254:194-200. [Crossref]

31. Ostrowski S, Johansson P (2012) Endothelial glycocalyx degradation induces endogenous heparinization in patients with severe injury and early traumatic coagulopathy. J Trauma Acute Care Surg 73: 60-66. [Crossref]

32. Zavodnik IB, Piasecka A, Szosland K, Bryszewska M (1997) Human red blood cell membrane potential and fluidity in glucose solutions. Scand J Clin Lab Invest 57: 5963. [Crossref]

33. Lee DH, Dane MJ, van den Berg BM, Boels MGS, van Teeffelen JW, et al. (2014) Deeper penetration of erythrocytes into the endothelial glycocalyx is associated with impaired microvascular perfusion. PLoS One May 9: e96477 [Crossref]

34. Frati Munari AC (2014) Medical significance of endothelial glycocalyx. Part 2: Its role in vascular diseases and in diabetic complications. Arch Cardiol Mex 84: 110-116. [Crossref]

35. Nieuwdorp M, Meuwese MC, Vink H, Hoekstra JB, Kastelein JJ, et al. (2005) The endothelial glycocalyx: a potential barrier between health and vascular disease. Curr Opin Lipidol 16: 507-511. [Crossref]

36. Koo A, Dewey C Jr., García-Cardeña G (2012) Hemodynamic shear stress characteristic of atherosclerosis-resistant regions promotes glycocalyx formation in cultured endothelial cells. Am J Physiol Cell Physiol 304: C137-C146. [Crossref]

37. Kolarova H, Ambruzova B, Svihalkova L, Klinke A, Kubala L (2014) Modulation of Endothelial Glycocalyx Structure under Inflammatory Conditions. Mediators of Inflammation; ID 694312.

38. Drake-Holland AJ, Noble MIM (2012) Update on the Important New Drug Target in Cardiovascular Medicine - the Vascular Glycocalyx. Cardiovasc Hematol Disord Drug Targets 12: 76-81. [Crossref]

39. Zhang X, Sun D, Song JW, Zullo J, Lipphardt M, et al. (2018) Endothelial cell dysfunction and glycocalyx - A vicious circle. Matrix Biol. [Crossref]

Copyright: (C2018 Drake-Holland AJ. This is an open-access article distributed under the terms of the Creative Commons Attribution License, which permits unrestricted use, distribution, and reproduction in any medium, provided the original author and source are credited. 